\title{
PERANCANGAN ENTERPRISE ARCHITECTURE E-COMMERCE PADA BAGIAN SHIPPING DI PT XYZ MENGGUNAKAN FRAMEWORK TOGAF ADM
}

\author{
${ }^{1}$ Chintamy Christini, ${ }^{2}$ Liane Okdinawati, ${ }^{3}$ Basuki Rahmad \\ 1,3 Program Studi Sistem Informasi - Fakultas Rekayasa Industri \\ ${ }^{2}$ Program Studi Teknik Industri - Fakultas Rekayasa Industri \\ 11chintamy.christini@gmail.com, ${ }^{2}$ aneu.okdinawati@gmail.com, ${ }^{3}$ basukirahmad@gmail.com
}

\begin{abstract}
Abstrak-PT XYZ adalah salah satu enterprise terkemuka di Indonesia yang memiliki lini bisnis baru yaitu e-commerce yang bernama PQR. Saat ini, PQR belum dapat memberikan keuntungan yang maksimal bagi PT XYZ. Oleh karena itu, dibutuhkan aktivitas front-end dan back-end dapat mendukung jalannya PQR dengan baik. Pada penelitian ini, bagian yang dibahas adalah shipping yang merupakan back-end dari PQR yang masih memiliki masalah berupa kurangnya integrasi antar bagian sehingga menyebabkan munculnya dua masalah bagian shipping. Untuk membangun layanan shipping yang baik, maka dibutuhkan Enterprise Architecture (EA) sebagai konsep yang dapat mengintegrasikan teknologi dan bisnis yang sedang berjalan. Perancangan EA membutuhkan sebuah tool dalam bentuk framework agar dapat memberikan gambaran yang jelas dari konsep bisnis dan teknologi yang dirancang. Framework yang digunakan adalah TOGAF ADM dimana memiliki kelebihan bahwa arsitek EA dapat memilih aktivitas yang dikerjakan secara bebas. Fase yang dirancang pada penelitian ini mulai dari fase A (Architecture Vision) hingga D (Technology Architecture) yang menghasilkan artifak-artifak yang dapat menjadi dasar pengembangan dan integrasi antar fungsi bisnis pada PQR bagian shipping.
\end{abstract}

Kata kunci: enterprise architecture, e-commerce, shipping, TOGAF ADM

\section{Pendahuluan}

PT XYZ yang merupakan salah satu enterprise yang di bawah BUMN (Badan Usaha Milik Negara) yang masih bertahan hingga saat ini di Indonesia dengan berbagai pergantian nama. Saat ini PT XYZ memiliki berbagai macam lini bisnis dan memiliki jaringan bisnis yang dapat ditemui di seluruh provinsi di Indonesia sebanyak 24.000 titik [1]. Salah satu cabang lini bisnis yang dijalani PT XYZ dalam bentuk penggunaan teknologi informasi (TI) adalah e-commerce yang dikenal sebagai PQR. Saat ini, PQR belum memberikan keuntungan yang besar bagi PT XYZ. Hal ini terlihat dari data transaksi pengiriman bulan Januari 2015 hanya sebesar 44 transaksi. Hal ini disebabkan oleh tujuan PQR yang awalnya untuk mendukung core bisnisnya yaitu pada bagian shipping dan payment.

Untuk mendukung layanan PQR, maka diperlukan aktivitas front-end dan back-end yang baik. Salah satu aktivitas back-end yang berpengaruh pada bisnis e-commerce adalah shipping (pengiriman). Shipping merupakan proses pengontrolan aliran barang ke tempat tujuan [2]. Saat ini, layanan shipping yang berjalan pada PQR hanyalah ada dua yaitu jangka waktu 2-4 hari dan jangka waktu 1 hari untuk produk durian. Oleh karena itu, pembeli tidak dapat memilih layanan pengiriman sesuai dengan keinginannya agar produk yang dipesannya dapat sampai lebih cepat atau lebih lambat dari waktu pengiriman. Masalah lainnya adalah ketidaktepatan waktu pengiriman produk PQR kepada pembelinya. Masalah ini dibuktikan dari data shipping selama bulan Januari hingga Februari 2015 dari 148 transaksi hanya 59 transaksi yang dikirimkan tepat waktu, hal ini terlihat pada Gambar 1. Masalah shipping secara umum adalah kurangnya integrasi antar bagian shipping dengan bagian lainnya sehingga menyebabkan adanya dua masalah bagian shipping tersebut.

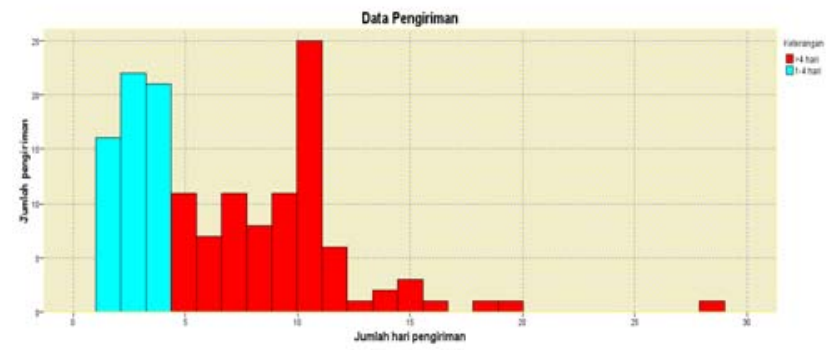

Gambar 1 Histogram data pengiriman

Oleh karena itu, untuk mendukung jalannya e-commerce ini maka akan dibuat perancangan dalam bentuk Enterprise Architecture untuk PQR pada bagian shipping. Enterprise Architecture (EA) adalah sebuah kesatuan dari prinsip, metode, dan model yang digunakan dalam mendesain dan merealisasikan struktur organisasi, proses bisnis, sistem informasi, dan infrastruktur dari sebuah enterprise [3]. Tujuan dari penerapan EA adalah untuk mengoptimalkan seluruh kegiatan yang ada di perusahaan, baik kegiatan yang bersifat manual maupun otomatis, ke dalam lingkungan yang terintegrasi dan tanggap terhadap perubahan dan mendukung pencapaian strategi bisnis [4]. Oleh karena itu, untuk menerapkan EA diperlukan framework agar dapat mempercepat dan menyederhanakan pengembangan arsitektur.

Salah satu framework yang dapat digunakan adalah TOGAF ADM. TOGAF ADM menyediakan suatu siklus proses spesifik yang terdiri dari delapan fase utama untuk pengembangan dan pemeliharaan arsitektur TI dari suatu 
organisasi atau perusahaan [5]. TOGAF ADM menjelaskan bahwa pengembangan EA menggunakan sebuah metode iteratif dalam bentuk siklus yang tidak berhenti (berupa lingkaran) karena ketika ada kebutuhan tambahan maka tahap sebelumnya dapat dikerjakan kembali [4]. Oleh karena itu, implementasi EA dianggap sebagai proses yang berkelanjutan oleh TOGAF ADM sehingga dapat digunakan untuk membangun PQR bagian shipping agar memberikan layanan membangun PQR bagian shipping agar memberikan layanan yang terintegrasi sehingga dapat memberikan kepuasan customer dan keuntungan yang berkelanjutan bagi PT XYZ.

\section{Metode Penelitian}

Metode penelitian dijelaskan dalam bentuk sistematika penelitian pada Gambar 2. Sistematika penelitian menjelaskan apa saja pekerjaan yang dilakukan pada perancangan EA penelitian ini dimana pada awalnya dilakukan analisis model bisnis existing dengan metode SWOT (Strength, Weakness, Opportunity, Threat) dan perancangan model bisnis target dengan Business Model Canvas (BMC) pada PQR.

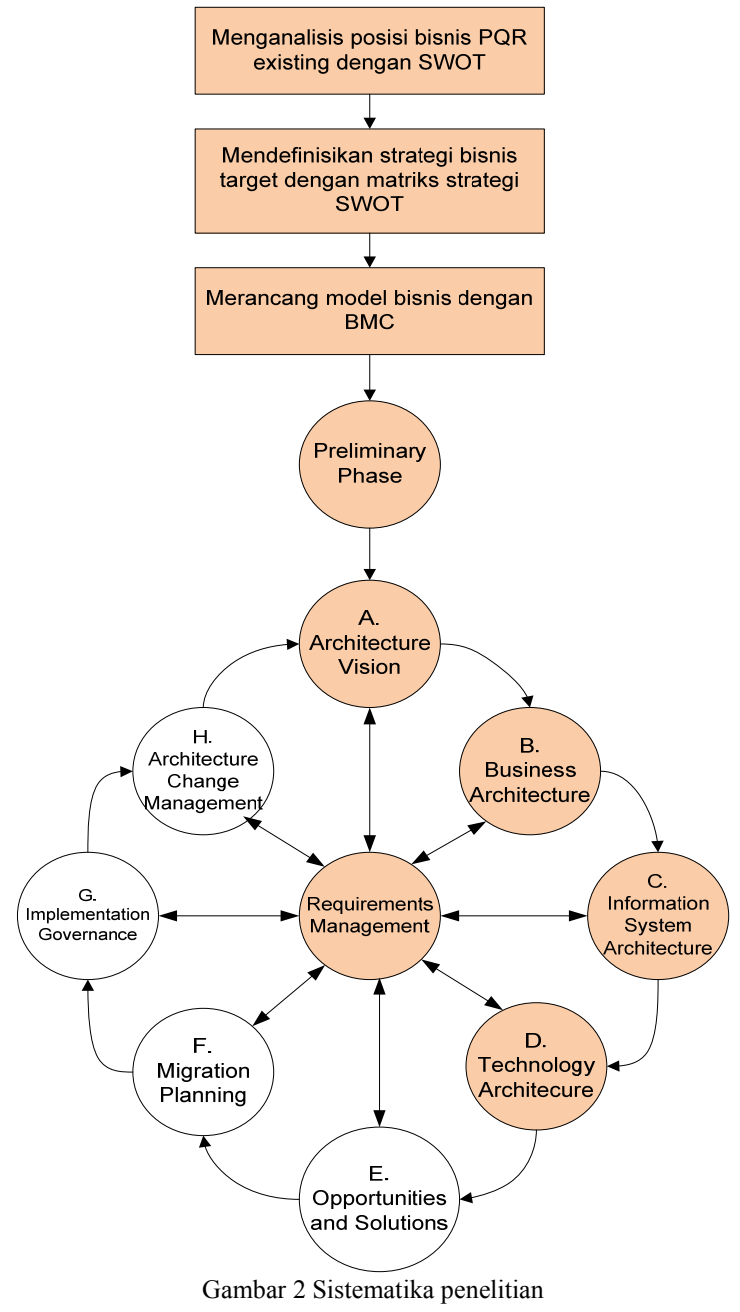

Dengan hasil perancangan model bisnis, maka prinsipprinsip pada fase Preliminary Phase dapat didefinisikan. Setelah itu, fase Architecture Vision hingga Technology Architecture dapat dirancang sesuai dengan pendefinisian prinsip yang telah dilakukan. Requirement management juga dilakukan ketika ada kebutuhan yang perlu ditambahkan pada setiap fase yang dirancang. Penelitian ini terbatas pada pengerjaan 4 fase pada $A D M$ Cycle karena fase selanjutnya dilakukan ketika implementasi akan diterapkan pada objek penelitian.

\section{HASIL DAN PEMBAHASAN}

\section{A. Posisi Bisnis Existing PQR}

Posisi bisnis existing PQR menggunakan metode SWOT. SWOT dapat meninjau lingkungan dimana unit bisnis dijalankan dan mengidentifikasi peluang yang ada di lingkungan dan ancaman yang ditunjukkan oleh lingkungan [5]. PQR memiliki empat kekuatan yaitu jaringan pengiriman yang luas, syarat menjadi supplier mudah, nama website mencerminkan perusahaan, dan sistem payment yang terpercaya. Di balik kekuatan tersebut, PQR masih memiliki 6 kelemahan yaitu display produk kurang menarik, kurangnya promosi produk dan website PQR kepada masyarakat, sistem payment bagi customer yang tidak bervariasi, jenis pengiriman tidak bervariasi, tidak adanya hak akses supplier terhadap webstore, dan kurangnya integrasi aplikasi antar bagian di $\mathrm{PQR}$. Dari lingkungan, peluang yang mendukung PQR adalah bisnis e-commerce yang sedang digemari oleh masyarakat, banyaknya jumlah UKM di Indonesia, produk lokal (UKM) yang berkualitas, masyarakat yang semakin mengenal internet, banyaknya jumlah penduduk Indonesia, dan kondisi geografis Indonesia. Sedangkan ancaman dari lingkungan adalah kompetitor luar negeri yang menjalankan bisnis e-commerce, kompetitor yang menjalani bisnis e-commerce di Indonesia, pedagang yang memiliki toko fisik, dan forum jual-beli di internet.

SWOT yang telah didefinisikan telah dibuat kuesioner untuk diberikan kepada pegawai PQR dan konsumen untuk dilakukan perhitungan analisis SWOT. Elemen SWOT dikelompokkan menjadi internal dan eksternal dan dilakukan pengurangan dari masing-masing elemen sesuai dengan bagian masing-masing. Dari hasil perhitungan didapatkan nilai strengths sebesar 331, weaknesses sebesar 342, opportunities sebesar 330, dan threats sebesar 315. Hasil perhitungan menunjukkan bahwa $\mathrm{PQR}$ berada di posisi stabilisasi. Posisi ini menjelaskan bahwa PQR sebenarnya cukup berpeluang dalam bisnis e-commerce namun keadaan internal PQR masih kurang kuat untuk mendukung PQR. Oleh karena itu dibutuhkan strategi-strategi agar PQR dapat menuju posisi pertumbuhan yang ada pada kuadran I. Strategi-strategi yang dapat digunakan adalah sebagai berikut:

1. Implementasi layanan shipping sesuai dengan kebutuhan.

2. Peningkatan kegiatan promosi. 
3. Peningkatan kompetensi dan kemampuan SDM dalam menguasai TI.

4. Pengembangan webstore yang fleksibel dan userfriendly.

5. Peningkatan variasi sistem payment (account-based).

6. Pengintegrasian aplikasi antar bagian di PQR.

7. Pemberian hak akses pada merchant.

8. Implementasi kontrol kualitas pada produk.

9. Pemberian hasil analisis sentimen pasar kepada merchant.

\section{B. Perancangan Strategi dengan Business Model Canvas (BMC)}

Dari pendefinisian strategi-strategi dari hasil analisis SWOT, maka model bisnis target dapat dibuat dengan metode BMC. BMC adalah model yang mengembangkan sebuah model bisnis baru atau mendokumentasikan atau memperbaiki model bisnis existing [6]. Oleh karena itu, BMC untuk bisnis PQR yang baru pada Gambar 3 dimana bagian shipping merupakan salah satu aktivitas kunci $\mathrm{PQR}$, memberikan value bagi customer berupa metode pengiriman yang bervariasi, dan bekerja sama dengan jasa pengiriman PT XYZ untuk melakukan pengiriman produk.

\section{Perancangan EA Bagian Shipping dengan TOGAF ADM}

Dari model bisnis yang dirancang dengan BMC, maka perancangan EA dengan TOGAF ADM untuk bagian shipping PQR dapat dilakukan dengan mendefinisikan prinsip-prinsip yang terkait dengan shipping, apa saja visi arsitektur yang terkait dengan shipping, bagaimana bisnis yang dirancang, sistem informasi apa saja yang dibutuhkan untuk mendukung kinerja bisnis, dan platform apa saja yang dibutuhkan untuk mendukung sistem informasi yang dirancang. BMC untuk PQR terlihat pada Gambar 3.

\section{Preliminary Phase}

Fase preliminary phase merupakan fase yang dilakukan untuk mempersiapkan materi yang akan digunakan sebagai bahan dalam perancangan arsitektur [7]. Prinsip-prinsip arsitektur didefinisikan pada fase ini dalam bentuk principles catalog untuk menjelaskan solusi yang baik yang akan dirancang pada fase selanjutnya [9]. Prinsip-prinsip yang terkait dengan bagian shipping adalah sebagai berikut:

TABEL I

PRINCIPLES CATALOG BAGIAN SHIPPING

\begin{tabular}{|l|l|l|}
\hline No & Nama Arsitektur & \multicolumn{1}{c|}{ Prinsip Arsitektur } \\
\hline 1. & $\begin{array}{l}\text { Business } \\
\text { Architecture }\end{array}$ & $\begin{array}{l}\text { - Layanan shipping sesuai kebutuhan } \\
\text { - Ketepatan waktu pengiriman } \\
\text { - Informasi pengiriman yang real- } \\
\text { time } \\
\text { - Kepercayaan }\end{array}$ \\
\hline 2. & Data Architecture & $\begin{array}{l}\text { - Sharing data } \\
\text { - Pengawasan data } \\
\text { - Integrasi data }\end{array}$ \\
\hline 3. & $\begin{array}{l}\text { Application } \\
\text { Architecture }\end{array}$ & $\begin{array}{l}\text { - Fleksibilitas aplikasi } \\
\text { - Integrasi aplikasi } \\
\text { - Implementasi online-tracking }\end{array}$ \\
\hline 4. & $\begin{array}{l}\text { Technology } \\
\text { Architecture }\end{array}$ & $\begin{array}{l}\text { - Penggunaan teknologi real-time } \\
\text { - Interoperabilitas }\end{array}$ \\
\hline
\end{tabular}

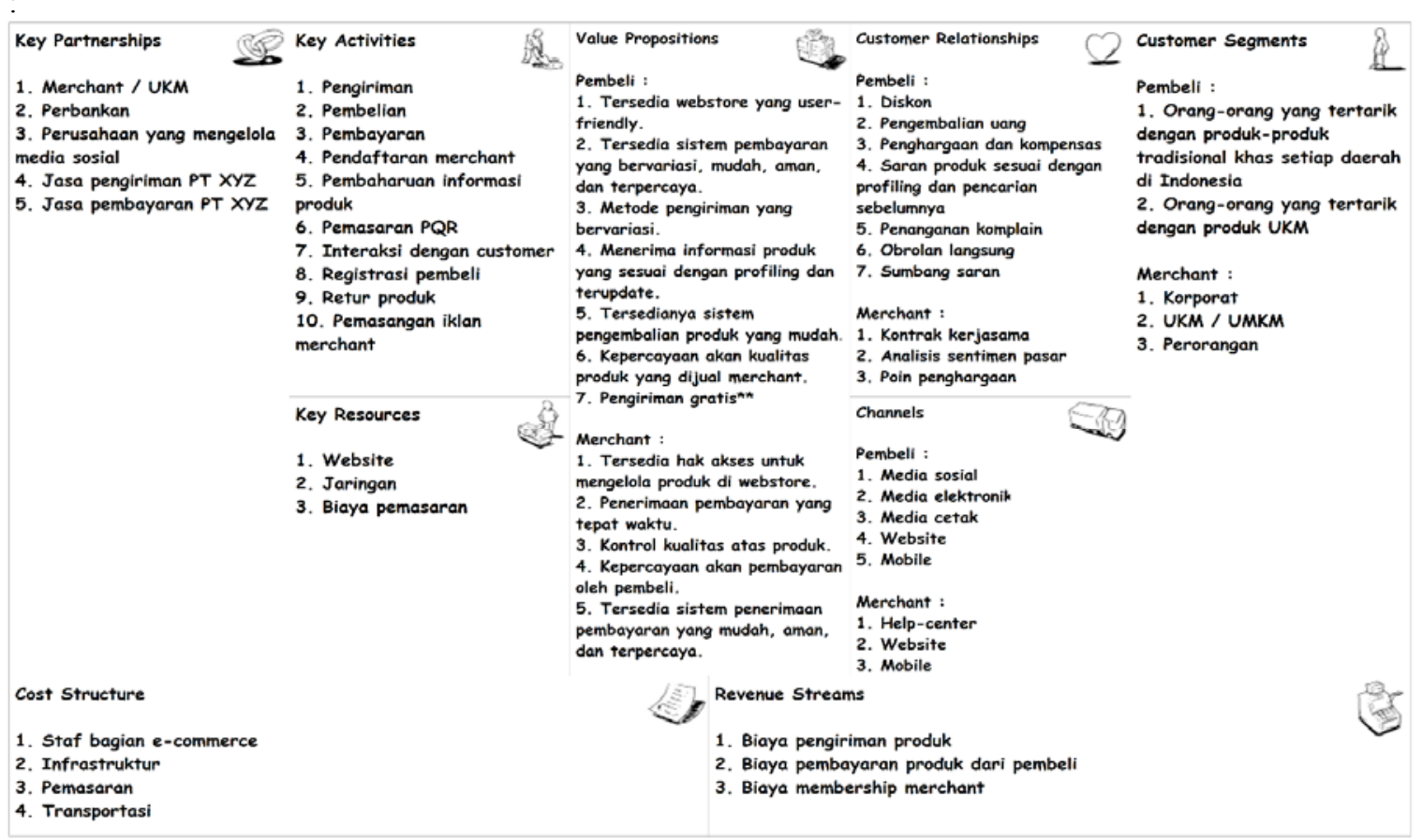

Gambar 3 Business Model Canvas untuk PQR 


\section{Architecture Vision}

Tahap Architecture Vision menggambarkan deskripsi arsitektur yang akan ditargetkan dari sudut pandang bisnis dan TI dan diharapkan arsitektur dapat difokuskan ke area yang penting untuk menilai kelayakan [10]. Tahap ini menghasilkan 3 artifak penting. Stakeholder map matrix mendeskripsikan stakeholder yang terlibat dengan enterprise architecture dan tanggung jawabnya. Stakeholder map matrix bagian Shipping terdiri atas 12 stakeholder internal dimana tanggung jawab bagian Shipping dilakukan oleh manajer dan staf Shipping and Delivery dan 13 stakeholder eksternal dimana bagian Shipping memiliki hubungan erat dengan Divisi Proses dan Transportasi PT XYZ. Value chain diagram menggambarkan bahwa bagian Shipping memberikan nilai pada aktivitas utama yaitu operasi berupa pengiriman dan proses monitoring pengiriman serta pada aktivitas pendukung yaitu infrastruktur berupa divisi Proses dan Transportasi PT XYZ. Solution concept diagram yang menggambarkan hubungan dari frontend dan back-end dari PQR terlihat pada Gambar 4 dimana shipping terdapat pada bagian mid office dan didukung oleh shipping PT XYZ pada back office.

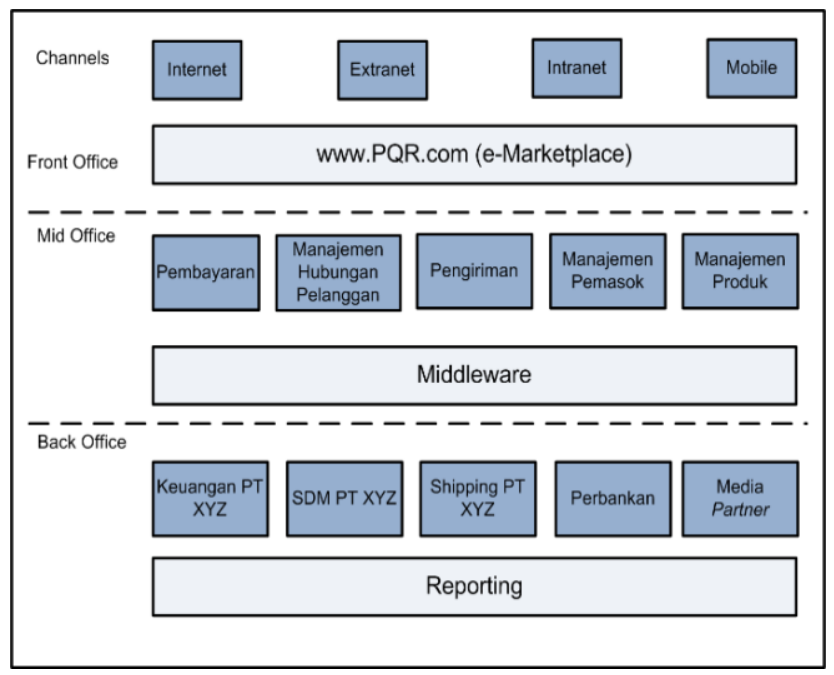

Gambar 4 Solution concept diagram PQR

\section{Business Architecture}

Arsitektur bisnis mendefinisikan strategi bisnis, pengelolaan, organisasi, dan proses bisnis utama [9]. Pada fase ini terbagi atas dua tujuan yaitu menggambarkan motivation extension membantu enterprise agar termotivasi untuk mencapai tujuannya dan core content merupakan artifak-artifak inti pada arsitektur yang dirancang. Salah satu artifak yang dapat menggambarkan motivation extension berupa drivers/goals/objectives catalog. Drivers/goals/objectives catalog menjelaskan sasaran, tujuan, dan penggerak bagian shipping untuk memberikan layanan terbaik bagi customer yang terlihat pada Tabel II. Dengan adanya artifak motivation extension, bagian shipping diharapkan dapat mendukung PQR untuk meningkatkan keuntungan bisnisnya. Sedangkan core content digambarkan dengan adanya business interaction matrix dan process flow.
Business interaction matrix menghasilkan pemetaan antara layanan enam fungsi bisnis yaitu e-Marketplace, manajemen produk, manajemen pemasok, payment, shipping dan manajemen hubungan pelanggan baik yang disediakan maupun dikonsumsi oleh keenam fungsi bisnis tersebut. Process flow menggambarkan proses bisnis shipping yang diusulkan sehingga aliran data untuk shipping tergambar jelas. Gambar 5 menggambarkan process flow yang dirancang pada bagian Shipping PQR bertanggung jawab atas pengiriman produk baik yang dipesan maupun yang diretur oleh customer. Pengiriman produk sistem pick-up dapat digunakan oleh merchant dengan syarat tertentu yaitu pesanan di atas 50 buah dengan ukuran minimal $30 \times 30 \mathrm{~cm}$. Jenis pengiriman lainnya adalah pengiriman langsung ke alamat tujuan customer atau kantor pos terdekat untuk mencegah tidak adanya orang yang dapat menerima produk pesanan di alamat tujuan. Bagian Shipping PQR juga bertanggung jawab atas proses pengawasan tracking agar kurir dapat mengirimkan produk secara tepat waktu. Setiap aktivitas juga terdapat pertukaran data dengan pihak eksternal PQR yaitu pembeli dan merchant (supplier). Oleh karena itu, artifak-artifak arsitektur bisnis yang dirancang membantu bagian shipping dari PQR dapat memiliki tujuan dan tanggung jawab yang jelas untuk membangun sistem shipping yang lebih baik sehingga dapat meningkatkan kepuasan customer dan meningkatkan keuntungan PQR.

TABEL II

DRIVERS/GOALS/OBJECTIVES CATALOG

\begin{tabular}{|c|l|}
\hline \multicolumn{2}{|c|}{ Drivers } \\
\hline 1. & Meningkatkan kepuasan customer dalam shipping. \\
\hline 2. & $\begin{array}{l}\text { Meningkatkan penggunaan sistem informasi dalam } \\
\text { shipping dan warehouse. }\end{array}$ \\
\hline \multicolumn{2}{|c|}{ Goals } \\
\hline 1. & Layanan pengiriman sesuai kebutuhan. \\
\hline 2. & $\begin{array}{l}\text { Meningkatkan kepercayaan customer akan layanan } \\
\text { pengiriman dan pergudangan produk. }\end{array}$ \\
\hline 3. & Menyediakan informasi real-time. \\
\hline \multicolumn{2}{|c|}{ Objectives } \\
\hline 1. & Adanya variasi bentuk pengiriman. \\
\hline 2. & $\begin{array}{l}\text { Adanya sistem yang mengawasi pengiriman sehingga } \\
\text { dapat tepat waktu sampai kepada pembeli. }\end{array}$ \\
\hline 3. & Implementasi sistem online-tracking. \\
\hline 4. & Integrasi dengan aplikasi bagian lainnya. \\
\hline
\end{tabular}

\section{Information System Architecture}

Information System Architecture menggambarkan apa saja sistem informasi berupa data dan aplikasi yang dibutuhkan untuk mendukung kinerja bisnis. Fase ini terbagi atas dua bagian yaitu Data Architecture dan Application Architecture.

\section{a. Data Architecture}

Data Architecture merupakan salah satu fase pada Information System Architecture. Fase ini mendeskripsikan struktur dari aset data logikal dan fisik dari sebuah organisasi dan sumber daya dalam mengelola data [9]. 


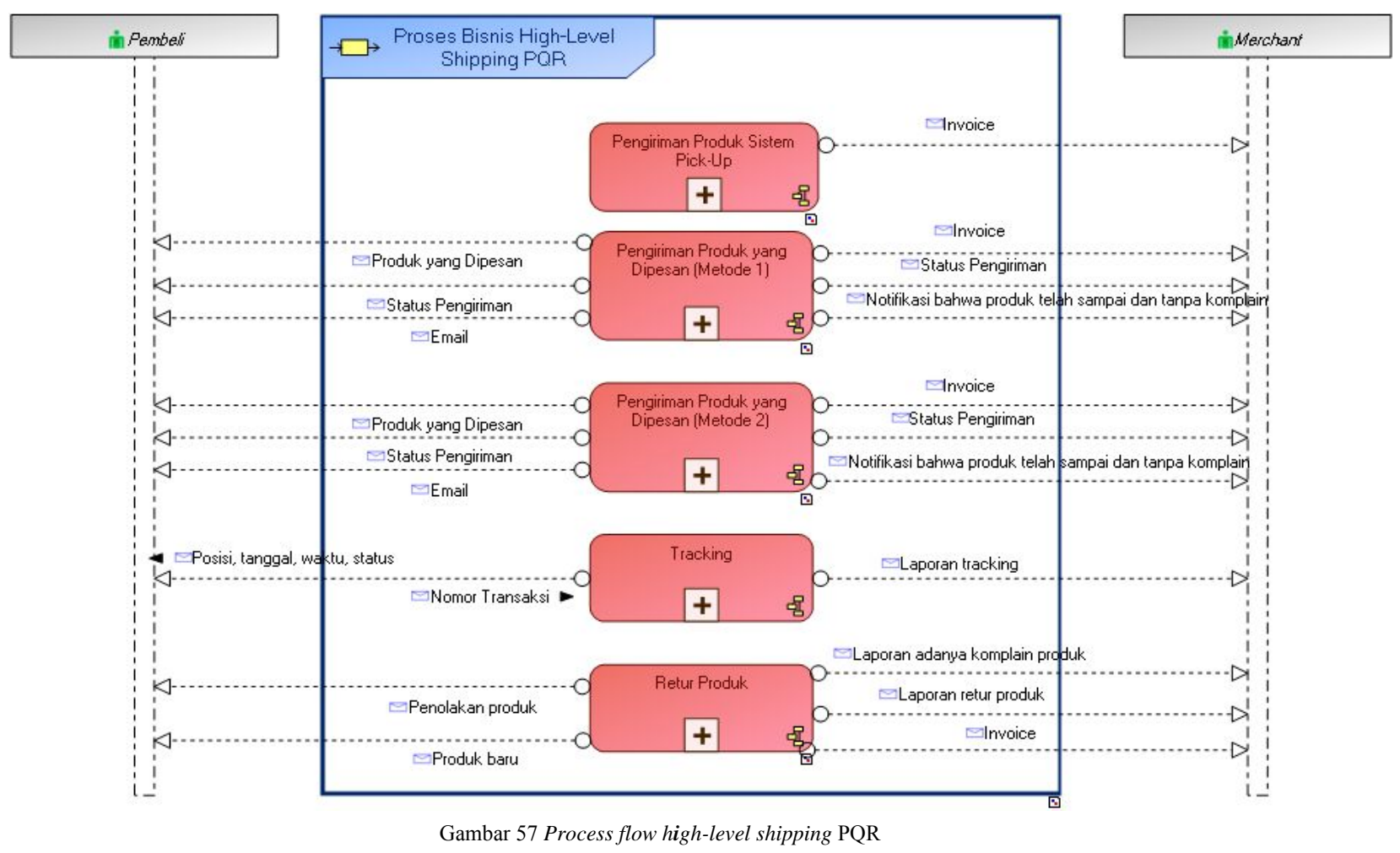

Beberapa artifak-artifak penting yang dihasilkan pada arsitektur ini yaitu data entity/data component catalog, data entity/business function matrix, dan data dissemination diagram. Data entity/data component catalog berisi daftar entitas data, logical data component, dan physical data component. Entitas data yang terkait dengan shipping adalah produk, merchant, shipping PT XYZ, pegawai, dan member. Sedangkan logical data component merupakan gabungan dua entitas data yaitu tracking, shipping, keluhan pelanggan (agar bagian shipping dapat menerima keluhan-keluhan yang terkait dengan pengiriman), transaksi pembayaran customer (untuk menerima notifikasi bahwa customer telah melakukan pembayaran), dan transaksi pembelian (agar shipping dapat langsung mengakses data yang diinputkan pelanggan sehingga tidak perlu diketik ulang saat supplier mengirimkan produk).

Data entity/business function matrix menjelaskan pemetaan antara entitas data dan fungsi bisnis yang berisi peran dalam bentuk CRUD (Create, Read, Update, Delete) dimana bagian shipping PQR menjadi penanggung jawab (melakukan aktivitas CRUD) terhadap data pengiriman dan tracking tetapi juga menggunakan data merchant (bagian manajemen produk dan supplier), data customer dan data keluhan pelanggan (bagian manajemen hubungan pelanggan).

Data dissemination diagram diperlihatkan pada Gambar 6 yang menjelaskan pengaksesan layanan bisnis shipping ke dalam pengelolaan kebutuhan data yang sesuai. Bagian shipping melakukan lima layanan bisnis yaitu pelaporan keterlambatan pengiriman dan pelaporan status pengiriman yang disebarkan ke semua bagian, penginformasian penanggungan biaya kirim oleh merchant yang diterima dari manajemen pemasok dan diteruskan ke bagian manajemen hubungan pelanggan, pelaporan produk yang gagal diterima untuk bagian manajemen produk, dan penginformasian online-tracking kepada bagian e-marketplace. Setiap layanan bisnis yang dilakukan pada bagian shipping membutuhkan beberapa logical application component yang merupakan pengelolaan data bagian lain dari $\mathrm{PQR}$ untuk mendukung kinerja dari shipping sehingga dapat memberikan layanan yang memuaskan customer yang dapat meningkatkan keuntungan dan kepercayaan customer kepada PQR.

b. Application Architecture

Application Architecture menyediakan sebuah cetak biru dari sistem aplikasi yang akan dikembangkan, interaksi dan relasi dengan proses bisnis inti dari organisasi [9]. Artifakartifak yang dihasilkan pada fase ini adalah Application Portfolio Catalog, Application Communication Diagram, dan Sequence Diagram. Application Portfolio Catalog terlihat pada Tabel III berisi pemetaan logical application component ke dalam physical application component dimana semua fungsi bisnis terintegrasi ke dalam satu aplikasi yaitu $e$ Marketplace PQR. Shipping juga didukung oleh sistem informasi shipping PT XYZ yaitu i-Shipping karena semua aktivitas pengiriman dilakukan oleh shipping $\mathrm{PT}$ XYZ.

Application Communication Diagram menjelaskan hubungan antara logical application component dan physical application component bagian shipping beserta pertukaran data dengan fungsi bisnis lainnya. Application Communication Diagram terlihat pada Gambar 7 menjelaskan 
bahwa bagian shipping sebenarnya bertanggung jawab atas pengelolaan shipping pada e-Marketplace PQR. Namun pengelolaan shipping tidak dapat berdiri sendiri untuk melakukan pekerjaannya melainkan membutuhkan pengelolaan bagian lain. Bagian shipping sendiri juga memberikan data-data yang diperlukan untuk bagian lain agar PQR dapat tetap berjalan lancar.

TABEL III

DRIVERS/GOALS/OBJECTIVES CATALOG

\begin{tabular}{|c|c|c|}
\hline No. & Logical Application Component & $\begin{array}{c}\text { Physical } \\
\text { Application } \\
\text { Component }\end{array}$ \\
\hline 1. & $\begin{array}{l}\text { Pengelolaan } \\
\text { Tracking }\end{array}$ & \multirow{6}{*}{$\begin{array}{l}\text { e-Marketplace } \\
\text { PQR }\end{array}$} \\
\hline 2. & Pengelolaan shipping & \\
\hline 3. & Pengelolaan keuangan & \\
\hline 4. & Pengelolaan produk dan pemasok & \\
\hline 5. & Pengelolaan keluhan pelanggan & \\
\hline 6. & Pengelolaan data pelanggan & \\
\hline 7. & Pengelolaan shipping PT XYZ & i-Shipping \\
\hline
\end{tabular}

Sequence Diagram memetakan bagaimana alur interaksi antar entitas data sehingga bagian Shipping dapat melakukan fungsinya dengan baik. Sequence Diagram yang dapat dibuat untuk bagaimana pengaksesan data oleh bagian shipping adalah permintaan tarif pengiriman oleh bagian pengelolaan sistem pembayaran, persiapan pengiriman dalam bentuk order pengiriman, bagaimana pembeli dapat melakukan tracking, pengawasan tracking agar dapat memberikan layanan yang tepat waktu kepada customer, memeriksa status pengiriman, memeriksa pengiriman ke i-Shipping ketika ada komplain dari customer mengenai keterlambatan pengiriman, mengirimkan status pengiriman kepada bagian lainnya yang memerlukan, dan memperbaharui penanggungan biaya kirim untuk proses retur produk. Ketiga artifak yang dibuat memperjelas integrasi antara bagian shipping dengan bagian lainnya dalam satu aplikasi bernama e-Marketplace PQR sehingga layanan shipping dapat memberikan layanan yang sesuai dan tepat waktu kepada customer.

\section{Technology Architecture}

Technology Architecture menjelaskan infrastruktur dari software yang mendukung penyebaran dari nilai dan aplikasi yang bersifat mission-critical [9]. Salah satu artifak utama yang dihasilkan dari fase ini adalah Environments and Locations Diagram. Environments and Locations Diagram menggambarkan pemetaan jaringan untuk mendukung $e$ Marketplace PQR dari empat user yaitu PT XYZ yang di dalamnya terdapat $\mathrm{PQR}$, customer, pemilik produk (merchant), dan mitra pembayaran dan teknologi yang digunakan pada setiap lokasi user. Diagram ini dapat dilihat pada Gambar 8.

Bagian shipping dapat dilihat pada lokasi bagian Shipping dan Delivery dimana terdapat teknologi berupa web client sebagai komputer yang mengakses aplikasi e-Marketplace PQR yang terhubung dengan switch. Switch pada bagian shipping terhubung dengan switch dengan spesifikasi yang lebih tinggi yang menghubungkan switch pada setiap bagian. Dari switch tersebut terdapat koneksi dengan load-balancing switch sebagai pengatur beban kerja untuk pengaksesan kepada web server yang menyediakan e-Marketplace PQR yang berada di bagian perencanaan dan pengembangan sistem teknologi.

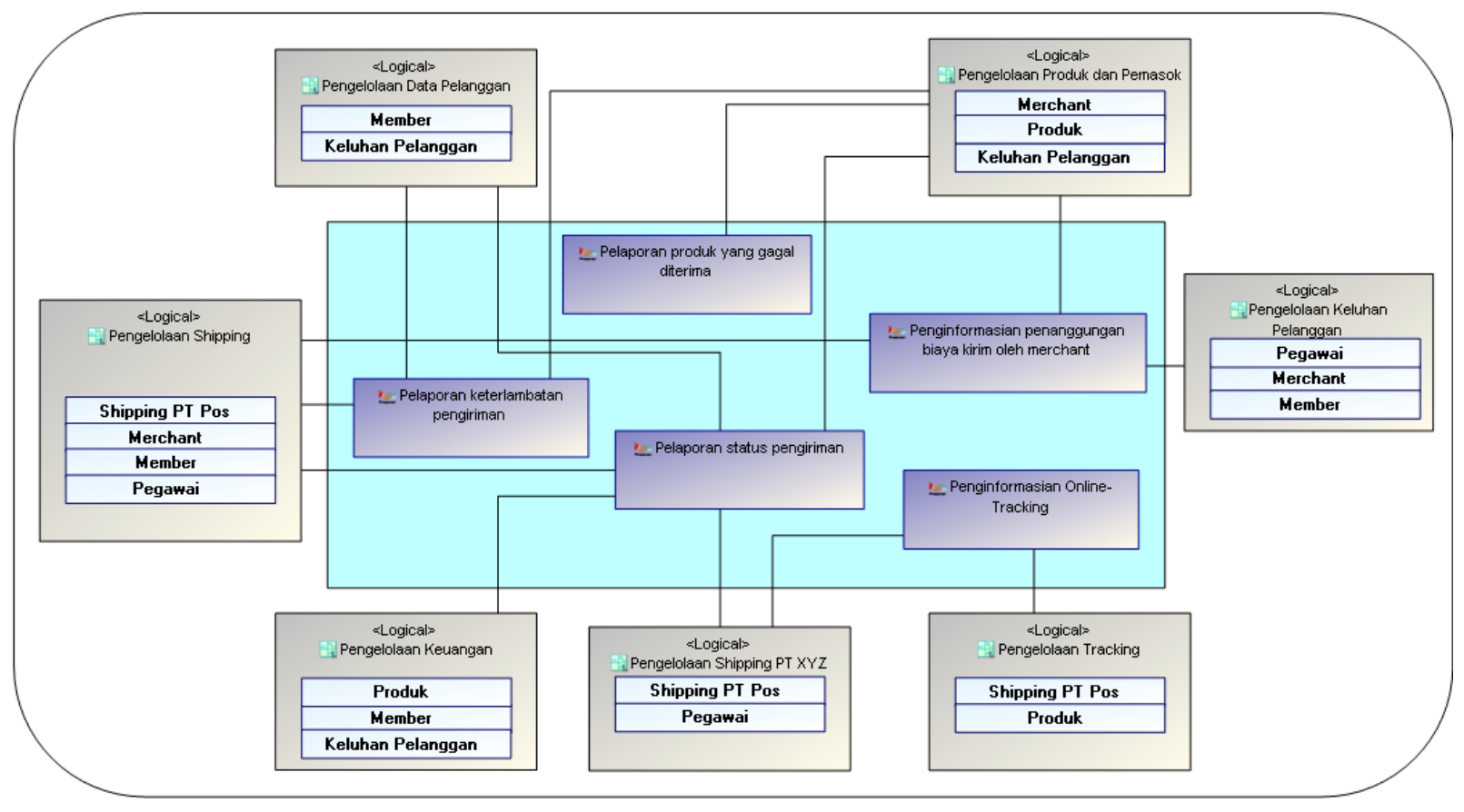

Gambar 6 Data Dissemination diagram shipping PQR 
Untuk menjaga beban kerja, web server back-up menjadi server cadangan sehingga performansi e-Marketplace PQR tetap terjaga. Kedua web server didukung oleh database server sebagai penyimpan data-data e-Marketplace PQR dan transaction processing server sebagai server yang memproses data-data transaksional untuk e-Marketplace PQR. Untuk mendukung pengaksesan e-Marketplace PQR secara luas baik dari internal maupun eksternal, maka dibutuhkan jaringan yang cukup besar dalam bentuk penggunaan WAN. Dari jaringan WAN terdapat dua firewall sebagai teknologi dalam menjaga keamanan pengaksesan e-Marketplace PQR yang dipisahkan oleh router. Arsitektur teknologi membantu penggambaran integrasi penggunaan teknologi pada setiap bagian yang saling terhubung satu sama lain sehingga kinerja layanan PQR dapat semakin membaik.

\section{KesimpUlan}

Dari hasil analisis dan perancangan model bisnis dan Enterprise Architecture PQR bagian shipping yang dilakukan pada penelitian, maka kesimpulan yang dapat diambil adalah analisis model bisnis existing PQR dan perancangan model bisnis target dengan menggunakan BMC merupakan dasar untuk melakukan perancangan EA. Perancangan EA bagian Shipping PQR menggunakan framework TOGAF ADM dari fase Preliminary Phase sampai Technology Architecture menghasilkan artifak-artifak yang menggambarkan konsep besar bagian Shipping PQR dari sisi bisnis, data, aplikasi, dan teknologi sehingga dapat mendukung model bisnis yang dirancang. Perancangan tersebut diharapkan dapat meningkatkan efektivitas dan optimalisasi integrasi antar bagian di dalam PQR yaitu mempermudah kinerja bagian shipping dalam berkomunikasi dengan bagian lainnya dan masalah ketidaktepatan waktu pengiriman dapat terpecahkan. Perancangan pada fase Business Architecture juga memberikan inovasi jenis pengiriman yang dapat dipilih oleh merchant dann customer sesuai dengan kebutuhan mereka. Oleh karena itu, perancangan EA ini dapat memberikan keuntungan yang lebih bagi $\mathrm{PQR}$ dalam meningkatnya efektivitas dan optimalisasi bagian Shipping dan melakukan inovasi yang dapat meningkatkan kepuasan customer.

Penelitian ini hanya terbatas pada proses perancangan EA bagian Shipping namun semua fungsi bisnis di dalam $e$ commerce sudah terintegrasi satu sama lain secara teoritis. Penelitian selanjutnya diharapkan dapat dilakukan testing mengenai analisa kelayakan dari bisnis PQR. Apabila penelitian ini dianggap layak, maka hasil penelitian diharapkan dapat diimplementasikan pada PQR sehingga PT $\mathrm{XYZ}$ dapat meneruskan PQR dengan tujuan yang jelas.

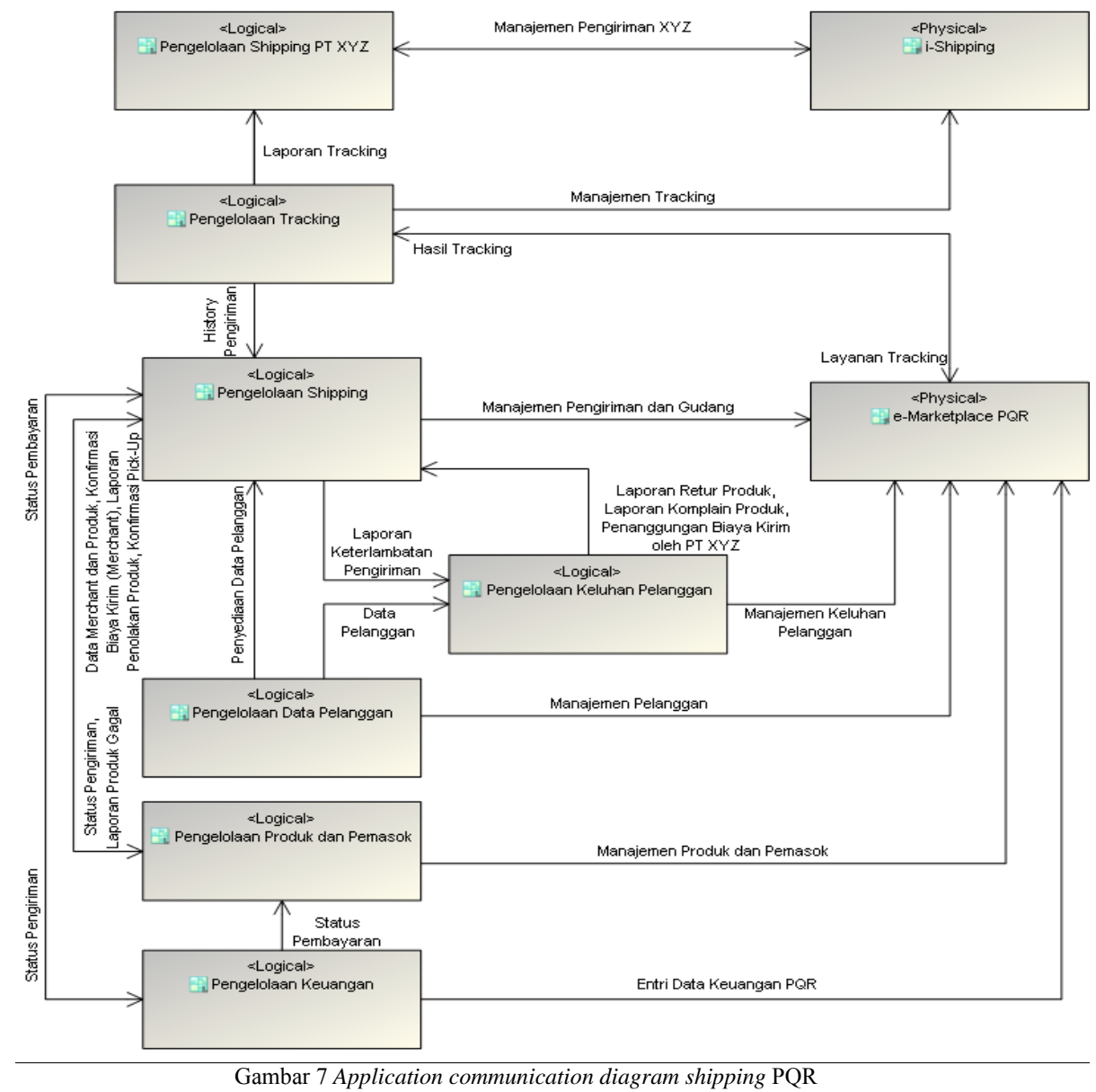




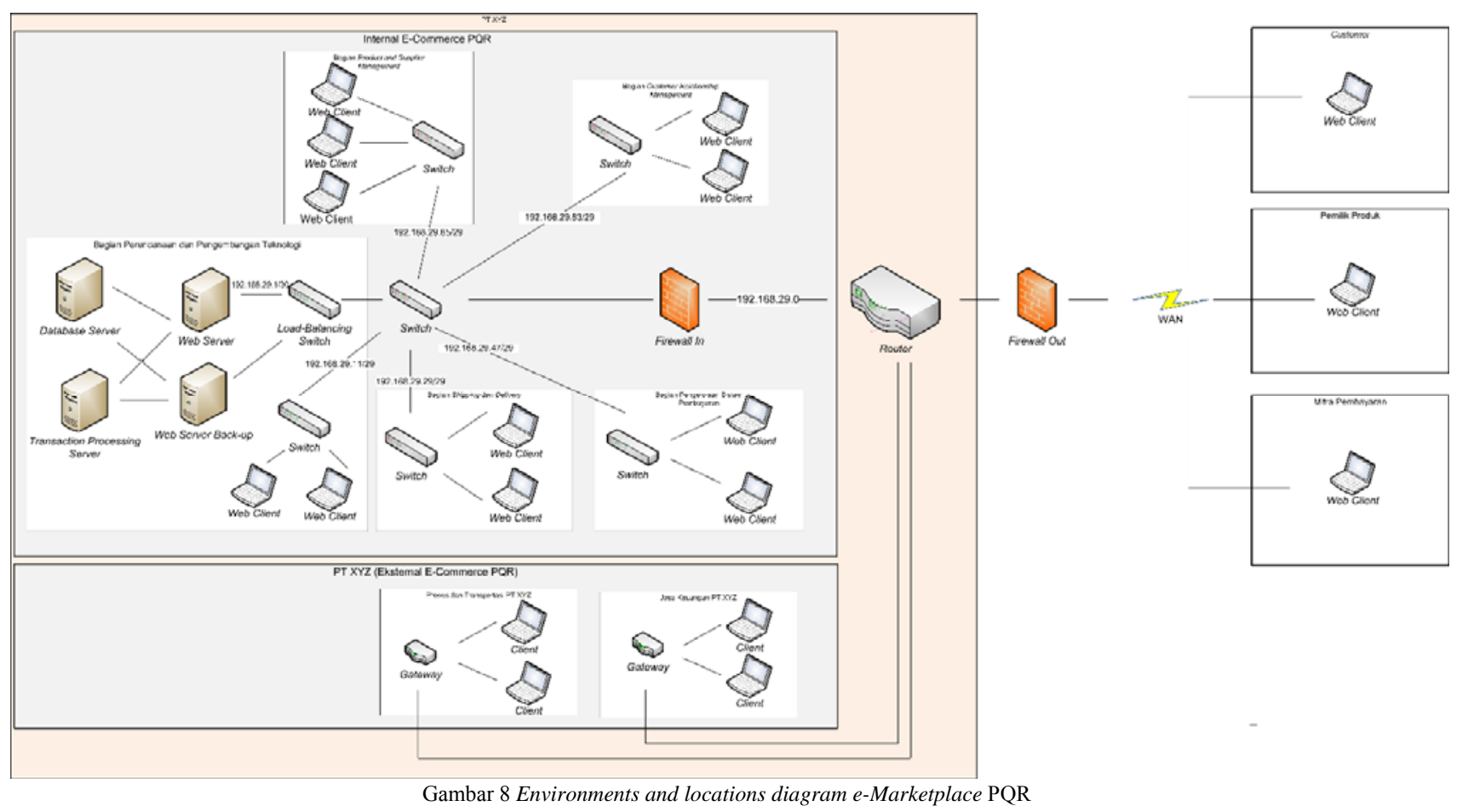

\section{DAFTAR PUSTAKA}

[1] PT XYZ, “www.xyz.co.id,” 2012. [Online]. Available: http://www.xyz.co.id/index.php/profil-perusahaan/. [Diakses 08 Oktober 2014].

[2] E. Turban, D. King, J. Lee dan D. Viehland, Electronic Commerce 2004 A Managerial Perspective, New Jearsey: Pearson Education Inc, 2004.

[3] K. Gonzali dan Y. G. Sucahyo, "Comparative Study of E-Government Enterprise Architecture by Primary Attributes of 3 Asian Countries," IEEE, p. 1, 2013.

[4] The Open Group, "TOGAF® Version 9.1, an Open Group Standard, Introduction,” 2009. [Online]. Available: http://pubs.opengroup.org/architecture/togaf9doc/arch/. [Diakses 09 Oktober 2014].

[5] M. O. Land, E. Proper, M. Waage, J. Cloo dan C. Steghuis, EA Creating Value by Informed Governance, Berlin: Springer-Verlag, 2009.

[6] D. B. Rouhani, M. N. Mahrin, F. Nikpay dan P. Nikfard, "A Comparison Enterprise Architecture Implementation
Methodologies," pp. 2-3, 2014.

[7] G. P. Schneider, Electronic Commerce 9th edition, 9 penyunt., United States of America: Cengage Learning, 2011, p. 4.

[8] A. Osterwalder, Y.Pigneur dan T.Clark, Business Model Generation : a handbook for visionarie, game changers, and challengers, Hoboken: Wiley, 2010.

[9] The Open Group, “Architectural Artifacts,” 2011. [Online]. Available: http://pubs.opengroup.org/architecture/togaf9doc/arch/chap35.html.

[10] The Open Group, [Online].

[11] X. Wang, X. Zhou dan L. Jiang, “A Method of Business and IT Alignment Based on Enterprise Architecture," IEEE, pp. 740-745, 2008. 